\title{
Analysis of 316L Stainless Steel Interaction with Galvanizing Alloy Bath
}

Abdul Khaliq ${ }^{1}$, Tayyab Subhani ${ }^{2}$ and Hafiz $\mathrm{Ali}^{3}$

${ }^{1}$ University of Hail, Saudi Arabia, Fawkner, Victoria, Australia, ${ }^{2}$ University of Ha'il, Hail, Ha'il, Saudi Arabia, ${ }^{3}$ Taif University, Taif, Makkah, Saudi Arabia

Steel products are coated with Zinc (Zn) and Aluminum (Al) based alloys for their protection against corrosive environments. For steel sheet coating, a continuous hot-dip galvanizing process is used in industry [1]. In this process, a clean steel sheet is passed through a molten alloy bath at a speed of 1-3 m/s and carry a liquid thin film upon exiting the bath. Thickness of the thin film is controlled by a pair of air knives installed at exit-point of the steel sheet [2]. The liquid thin film then solidifies into a coating alloy layer that protects the base metal (steel sheet) against corrosive environments. A schematic diagram of the coating alloy bath is given elsewhere [3]. Considering the intense reactivity of plain carbon steel with Al, pot gears such as snout, sink and guiding rolls are made from 316L stainless steel (SS). However, surface modification and intermetallic particles build-up on the sink roll surface led to deteriorating the coating quality of steel sheets. This resulted in early shut-down of the galvanizing hot-dip coating lines and replacement of the sink roll prior to their expected service life. This study investigated the interaction of $316 \mathrm{~L} \mathrm{SS}$ with Al-Zn-Si coating alloy bath at $600^{\circ} \mathrm{C}$.

Laboratory-scale experiments were conducted by dipping $316 \mathrm{~L}$ SS rods (10mm in diameter) in the iron (Fe) saturated $55 \% \mathrm{Al}-43 \% \mathrm{Zn}-1.6 \% \mathrm{Si}$ alloy bath. The bath temperature was controlled in the range of $600 \pm 2{ }^{\circ} \mathrm{C}$ by immersing a K-type thermocouple in the crucible. Stainless Steel samples were removed from the alloy bath after 7 days and analyzed for the change in microstructure and hardness.

Figure 1 shows optical microscopy images of as-received and hot-dipped 316L SS samples that were held for 7 days in molten Al-Zn-Si alloy. Figure 1(b) shows the formation of two distinct alloy layers at the interface of SS and Al-Zn-Si alloy. These alloy layers are designated as AL-1 and AL-2. The AL-1 formed between SS and AL-2 and that of AL-2 is found between AL-1 and coating alloy. It is evident from Figure 1(b) that intense chemical reaction has taken place between 316L SS and coating alloy bath. It has been reported in literature that $\mathrm{Fe}_{2} \mathrm{Al}_{5}$ and $\mathrm{FeAl}_{3}$ intermetallic phases formed in Al-Fe binary system [4]. However, in this study multicomponent system is under investigation that makes difficult to predict thermodynamically stables phases. Chemical composition of both alloy layers were determined by energy dispersive $\mathrm{X}$-day spectrometer analysis (EDS) that are shown in Figure 1(c \& d). The AL-1 contains $50.2 \% \mathrm{Al}, 33.4 \% \mathrm{Fe}, 7.4 \% \mathrm{Cr}, 3.5 \% \mathrm{Ni}$ and $4.7 \% \mathrm{Zn}$ that corresponds to $\mathrm{FeAl}_{3}$ in addition to elements such as $\mathrm{Cr}, \mathrm{Ni}$ and $\mathrm{Zn}$ (probably form solid solution). The AL-2 phase contains $55.9 \% \mathrm{Al}, 23.7 \% \mathrm{Fe}, 5.3 \% \mathrm{Cr}$, $4.1 \% \mathrm{Ni}, 3.9 \% \mathrm{Si}$ and $2.8 \% \mathrm{Zn}$ that is different to AL-1. It can be suggested that alloy layers are growing into molten alloy bath by diffusion of $\mathrm{Fe}$ and $\mathrm{Al}$ atoms in opposite directions.

The change in surface properties of 316L SS samples were analysed by the Vicker Hardness (HV) method that are shown in Figure 2. The HV hardness was measured at 316L SS, AL-1 and AL-2 and is shown in Figure 2(b). It can be observed that hardness of the 316L SS has increased from $231.3 \mathrm{HV}$ to $873 \mathrm{HV}$ that makes sink roll surface extremely hard and brittle. The AL-2 hardness is $\sim 3$ times to that of $316 \mathrm{~L}$ SS, therefore, cracks can be observed in Figure 1(b). It can be concluded from this study that 316L SS also reacts with the Al-Zn-Si coating alloy bath at $600^{\circ} \mathrm{C}$. The intermetallic alloy layers (AL-1 \& AL-2) formed at the interface of 316LSS and Al-Zn-Si alloy are hard and brittle that significantly alter surface properties of the sink roll. It is recommended to investigate alternative materials that have limited reactivity with 
molten Al-Zn-Si alloy bath and possess required surface properties. In addition 316L SS surface modification is another way to improve service life of the sink roll used in the continuous hot-dip galvanizing processes.

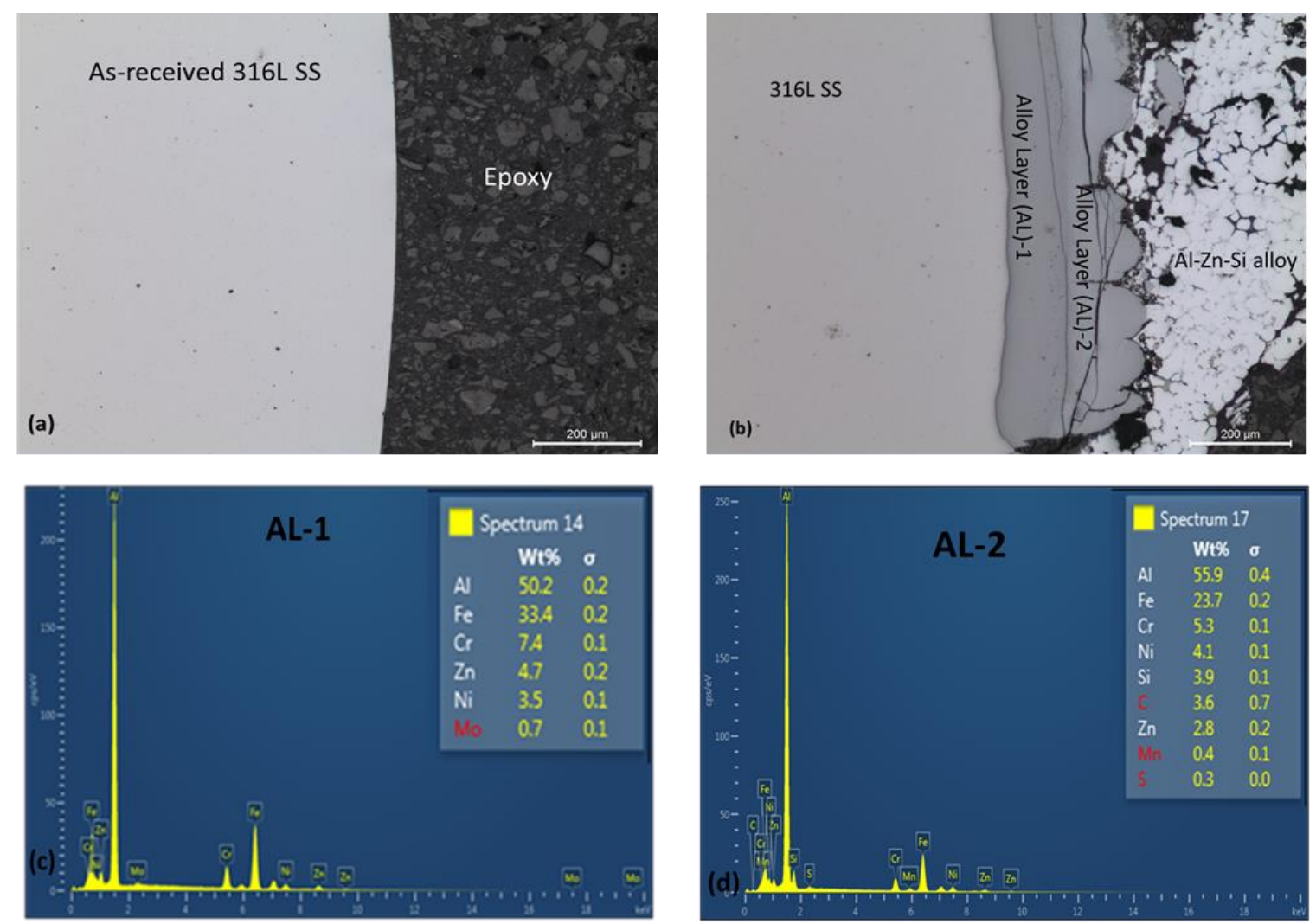

Figure 1. Optical microscopic images (a). As-received 316L Stainless Steel, (b). After 7-day hot-dipping, (c). EDS analysis of AL-1, (d), EDS analysis of AL-2
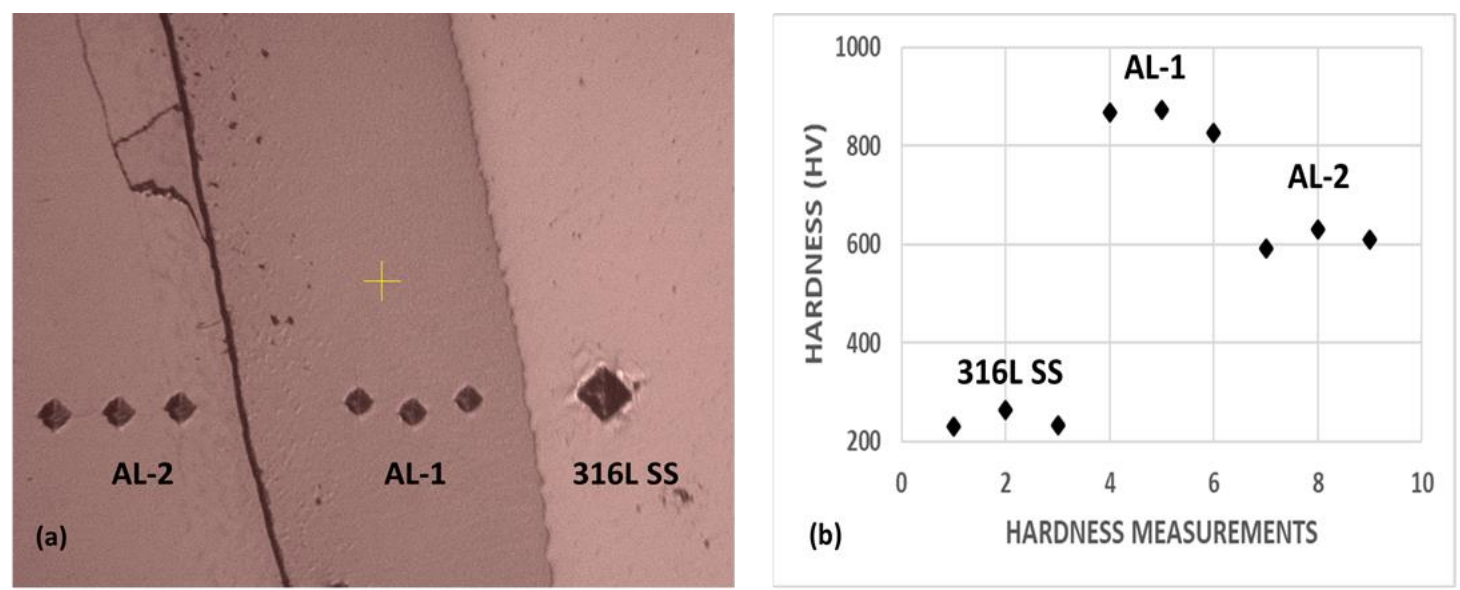

Figure 2. Vicker's hardness (HV) testing of 316L Stainless Steel rod hot-dipped for 7 days (a). Optical microscopy image showing indentation marks, (b). HV profile of 316L stainless steel, AL-1 and AL-2

\section{References}

[1] A.R. Marder: Prog. Mater. Sci., 2000. 45(3): p. 191-271

[2] N. Setargew, J. Hodges and D. J. Parker: Steel Research Hub, Australia, unpublished research, 2015. 
[3] A. Khaliq, D. J. Parker, N. Setargew and M. Qian, Metall. and Materi. Trans. B (2020). https://doi.org/10.1007/s11663-019-01765-Z

[4] X. Li, A. Scherf, M. Hellmaler and F. Stein, J. of Phase Equilibria and Diffusion, 2016. 37(2), 162173 